\title{
Análise da sustentabilidade de uma intervenção de promoção da saúde no município de Recife, Pernambuco
}

| ${ }^{1}$ Gisele Cazarin, ${ }^{2}$ Ana Cláudia Figueiró, ${ }^{3}$ Sónia Ferreira Dias, ${ }^{4}$ Zulmira Hartz |

Resumo: Iniciativas de promoção de atividade física têm sido apontadas como relevantes na promoção da saúde. O município de Recife, Pernambuco, idealizou e implantou em 2002 política dessa natureza, denominada Programa Academia da Cidade (PAC). A sustentabilidade de intervençóes de promoção da saúde constitui um desafio à manutenção dos seus resultados. Objetivou-se analisar o percurso dos eventos relativos à sustentabilidade do PAC Recife no período de 2002 a 2016. Trata-se de pesquisa avaliativo-qualitativa, tendo como estratégia de estudo o caso único. Para a análise dos dados, empregou-se a análise de conteúdo temática. Recolheram-se dados por meio da técnica do incidente crítico, em 14 entrevistas com informantes-chave e seis grupos focais, em dois períodos: de agosto a dezembro de 2010 e de junho a agosto de 2016, e em documentos oficiais e técnicos. Construiu-se a linha do tempo dos eventos/incidentes críticos relativos à sustentabilidade do programa. Os dados foram analisados conforme as seguintes categorias: eventos de implementação, mistos e de sustentabilidade. Os eventos ficaram classificados de acordo com suas consequências em favoráveis ou desfavoráveis à sustentabilidade. Os resultados indicaram ocorrência de 14 eventos/incidentes críticos, na maior parte com consequências positivas para a continuidade do programa no período estudado.

> Palavras-chave: avaliação em saúde; sustentabilidade; promoção da saúde.

\author{
${ }^{1}$ Instituto de Medicina Integral \\ Professor Fernando Figueira. Recife- \\ PE, Brasil (gcazarin@gmail.com). \\ ORCID: 0000-0003-3663-4665. \\ ${ }^{2}$ Escola Nacional de Saúde Pública \\ Sergio Arouca, Fundação Oswaldo \\ Cruz. Rio de Janeiro-RJ, Brasil \\ (anaclaudiafigueiro@gmail.com). \\ ORCID: 0000-0003-0718-5426. \\ ${ }^{3}$ Escola Nacional de Saúde \\ Pública, Universidade Nova de \\ Lisboa. Lisboa, Portugal (smfdias@ \\ yahoo.com) \\ ORCID: 0000-0001-5085-0685. \\ ${ }^{4}$ Instituto de Higiene e Medicina \\ Tropical, Universidade Nova de \\ Lisboa. Lisboa, Portugal (zhartz@ \\ ihmt.unl.pt). \\ ORCID: 0000-0001-9780-9428.
}

Recebido em: 15/01/2019 Aprovado em: 17/05/2019 Revisado em: 03/07/2019 


\section{Introdução}

Nas últimas décadas, diversos autores (SCHEIRER, 2005; DIJKMAN et al., 2015; OLIVEIRA; POTVIN; MEDINA, 2015) vêm destacando a importância de o desenvolvimento de políticas de promoçáo da saúde (PS) ser acompanhado da análise da sua sustentabilidade, tida como a necessária continuidade dos efeitos positivos das intervençóes (PLUYE; POTVIN; DENIS, 2004). Essa preocupação fundamenta-se na existência de latência entre o início das atividades e os efeitos sobre a saúde. Dessa forma, intervenções sustentadas permitem manter seus efeitos de longo prazo (PLUYE; POTVIN; DENIS, 2004; PLUYE et al., 2004).

Além disso, diante da escassez de recursos e da crescente agenda governamental, cabe optar por intervençôes que, além de possibilitarem uma solução oportuna para as situações problemáticas a serem enfrentadas, tenham possibilidade de manutenção (OLIVEIRA; POTVIN; MEDINA, 2015).

No campo da Saúde Coletiva, o conceito de sustentabilidade tem sido refletido e aplicado por diversos teóricos de PS (PLUYE; POTVIN; DENIS, 2004; PLUYE et al., 2004; PLUYE et al., 2005; SCHEIRER, 2005; MENDES et al., 2014; DIJKMAN et al., 2015). Ao realizarem estudo advindo da literatura sobre a temática, Oliveira, Potvin e Medina (2015) apontaram que muitas são as nomenclaturas utilizadas para denominá-la, como manutenção, continuação, duração, perenização, rotinização, institucionalização e incorporação. Não havendo concordância sobre sua conceituação, nem tampouco sobre os fatores que influenciam na continuidade das intervençôes, e concluíram que o tema tem sido pouco explorado na literatura.

Essas autoras identificaram os seguintes domínios, propostos por diferentes autores, que afetam a sustentabilidade de intervençôes:

1) adaptação, com flexibilidade para transformar-se ao longo do tempo, de acordo com o contexto (O'LOUGHLIN et al., 1998; SHEDIAC-RIZKALLAH; BONE, 1998; PLUYE et al., 2004; PLUYE; POTVIN; DENIS, 2004; SCHEIRER, 2005; SCHEIRER; DEARING, 2011; SCHELL et al., 2013);

2) aprendizagem organizacional, com formação permanente e baixa rotatividade da equipe envolvida (O'LOUGHLIN et al., 1998; PLUYE et al., 2005; SCHELL et al., 2013);

3) apoio organizacional e parcerias, com criação de ambiente político interno favorável; integração à missão institucional; e a presença de "defensores", que 
possam lutar pelas intervençóes em períodos vulneráveis (O'LOUGHLIN et al., 1998; SHEDIAC-RIZKALLAH; BONE, 1998; PLUYE; POTVIN; DENIS, 2004; SCHEIRER, 2005; FELISBERTO et al., 2010);

4) financiamento, com recursos contínuos e suficientes advindos de múltiplas fontes (SHEDIAC-RIZKALLAH; BONE, 1998; PLUYE et al., 2005; SCHELL et al., 2013);

5) manutenção de benefícios, com percepção pelos participantes de que a intervenção está produzindo os resultados iniciais desejados (PLUYE; POTVIN; DENIS, 2004; SCHEIRER, 2005).

Pluye et al. (2004; 2005) denominam "rotinização" o processo primário que conduz ao estabelecimento de rotinas pelas quais a sustentabilidade é alcançada. Assim, a evolução de "eventos" se dá como unidades de observação relevantes para o estudo desse processo, uma vez que são dispostos numa sequência com ordenamento geralmente temporal, constituindo-se num instrumento analítico que permite reconstruir e analisar o desenvolvimento das intervençóes. Embora o termo evento remeta a uma precisão temporal, ele pode se referir a qualquer coisa como um ano ruim, uma fusão, uma decisão, uma reunião, uma conversação ou um aperto de mão (PLUYE et al., 2004; 2005).

Na visão de Pluye et al. (2004; 2005), os eventos devem ser caracterizados como processos de implementação e sustentabilidade, que acontecem concomitantemente. Alguns eventos influenciam especificamente a sustentabilidade; outros, a implementação; e outros influenciam ambos, sendo denominados eventos mistos. A análise do percurso de uma intervenção permite compreender os eventos concretos vivenciados pelos atores como um sistema dinâmico resultante de espaços negociados. Nesses espaços, as ações, em constante evolução, promovem mudanças na intervenção, e a análise desse processo elucida os mecanismos que contribuíram para o alcance dos seus efeitos de forma duradoura (POTVIN; CHABOT, 2002; BISSET; POTVIN, 2007; HARTZ; SANTOS; MATIDA, 2008; JOLY et al., 2015).

Considerando-se a análise da sustentabilidade de programas de PS como essencial ao fortalecimento das intervençóes, bem como a escassez de publicações no contexto nacional relacionadas à temática (FELISBERTO et al., 2010; OLIVEIRA; POTVIN; MEDINA, 2015), o presente estudo objetiva analisar o percurso dos 
eventos relativos à sustentabilidade do Programa Academia da Cidade (PAC) do município de Recife, Pernambuco, desde sua origem (2002) até 2016.

O PAC é uma intervenção de base comunitária implementado em espaços públicos em diversos bairros da cidade, em sua maioria em áreas de maior vulnerabilidade. É composto por 42 polos (locais construídos ou reformados ao ar livre para esse fim), e entre seus objetivos estão o estímulo à prática regular de atividade física orientada por educadores físicos, a orientação à alimentação saudável e a inclusão social. Cada polo conta com, ao menos, um educador físico que realiza avaliaçâo geral da condição de saúde dos usuários, orientando e encaminhando os problemas para os serviços de atenção primária. Desenvolve suas atividades com apoio de profissionais de nutrição e de saúde, e envolve os participantes em açóes sociais e recreativas.

\section{Método}

Trata-se de pesquisa avaliativa com foco na análise da sustentabilidade do Programa Academia da Cidade (PAC) do município de Recife, Pernambuco. A estratégia de pesquisa utilizada foi o estudo de caso único com níveis de análise imbricados (indivíduos - profissionais, usuários, gestores; projetos — polos de atividades e suas açôes; e organização - Secretaria de Saúde) (YIN, 2015). O caso foi definido conforme as recomendaçôes de Yin (2015) na condução de um estudo de caso único: caso peculiar ou exemplar, em que o desenho de casos múltiplos ou uma amostra estatisticamente representativa seria inviável. ${ }^{1}$

O estudo empregou abordagem qualitativa, e a coleta de dados utilizou a técnica de incidentes críticos (FLANAGAN, 1973). Incidentes críticos são situaçôes relevantes, observadas e relatadas pelos sujeitos entrevistados, podendo ser positivos ou negativos em função de suas consequências para a continuidade do programa (FLANAGAN, 1973; PLUYE et al., 2004; 2005; FELISBERTO et al., 2010). Os informantes-chave relatam, assim, fatos e situaçóes marcantes quando da sua vivência com o programa, durante um período de tempo determinado pelo pesquisador.

Os procedimentos de coleta dos dados foram entrevistas individuais, grupos focais e revisão de documentos oficiais e técnicos. O período de referência levou em conta fatos/situações transcorridos de 2002 a agosto de 2016. Os fatos/situaçôes acontecidos desde a instituição do programa (2002) até dezembro de 2010 foram coletados por intermédio de pesquisa anterior (FIGUEIRÓ et al., 2014). 
No primeiro período de coleta (agosto a dezembro de 2010), foram realizadas quatro entrevistas, a partir da pesquisa anteriormente citada (FIGUEIRÓ et al., 2014); as demais (dez), no segundo período de coleta (maio a agosto de 2016). Os informanteschave foram eleitos de forma intencional, de acordo com sua expertise em atividades de pesquisa, ensino, gestão e atuação profissional com o programa estudado.

Foram realizados dois grupos focais no primeiro período de coleta, sendo um com coordenadores pedagógicos distritais (seis integrantes) e outro com profissionais dos polos (oito integrantes). Já no segundo período, foram conduzidos quatro grupos focais: dois grupos com usuários (cada um com seis integrantes), um com coordenadores pedagógicos distritais (seis integrantes) e um com profissionais dos polos (sete integrantes). Totalizando seis grupos focais distintos. Os documentos oficiais e técnicos analisados foram identificados com o auxílio dos participantes da pesquisa (projetos, relatórios, atas de reuniōes, entre outros) e revisão de publicaçôes sobre o programa.

Para análise do material produzido pelas entrevistas e grupos focais, empregou-se a análise temática de conteúdo (BARDIN, 2011) adaptada, considerando as categorias conceituais preestabelecidas, presentes nos instrumentos de coleta de dados (HSIEH; SHANNON, 2005). Procedeu-se à interpretação por meio da classificação das falas e da leitura minuciosa e repetida do material transcrito, considerando tanto as categorias predefinidas quanto aquelas que emergiram do material empírico. Como instrumento auxiliar na sistematização dos eventos relativos à sustentabilidade do PAC no período estudado, elaborou-se uma linha do tempo do programa, útil na identificação dos eventos em um dado período (JOLY et al., 2015).

Apenas os incidentes críticos foram retidos para a etapa de análise dos dados. Estes foram analisados e interpretados de acordo com as categorias analíticas propostas por Pluye et al. (2005), e adaptadas por Felisberto et al. (2010), que os classificam por tipo de evento em: 1) implementação; 2) implementação e sustentabilidade; e 3) sustentabilidade.

A definição das categorias de análise utilizadas encontra-se no quadro 1 . Considerou-se como favorável o evento/incidente crítico cujas consequências foram interpretadas como positivas em relação à continuidade do programa. Já os desfavoráveis foram interpretados como fatos/situaçôes adversos à sustentabilidade (FELISBERTO et al., 2010). 
Quadro 1. Definiç̧âo das categorias analíticas para análise da sustentabilidade

\begin{tabular}{|c|c|}
\hline Categorias & Definição/critérios \\
\hline Sustentabilidade & \multirow{2}{*}{$\begin{array}{l}\text { Estabilização de recursos organizacionais (financeiros, } \\
\text { humanos, educação permanente, materiais/físicos) dedicados ao } \\
\text { programa. Com renovação de recursos materiais/equipamentos } \\
\text { (quando necessário). }\end{array}$} \\
\hline $\begin{array}{l}\text { Estabilização e/ou } \\
\text { renovaçáo de recursos }\end{array}$ & \\
\hline $\begin{array}{l}\text { Riscos assumidos pela } \\
\text { organização em prol dos } \\
\text { programas }\end{array}$ & $\begin{array}{l}\text { Exploração e adoção de atividades novas no nível } \\
\text { organizacional para fins de apoio à continuidade do programa } \\
\text { (“apostas”); com mescla de atividades novas e antigas, e criação, } \\
\text { por parte da organização, de ambiente político interno favorável } \\
\text { (apoio além do financeiro), com construção de confiança entre } \\
\text { os envolvidos. }\end{array}$ \\
\hline $\begin{array}{l}\text { Implantação e } \\
\text { sustentabilidade }\end{array}$ & \multirow{2}{*}{$\begin{array}{l}\text { Implantação de políticas de valorização do trabalhador, adoção } \\
\text { de incentivos (financeiros: plano de cargos, carreiras e salários, } \\
\text { gratificaçóes, contrato/acordo de gestão e produtividade, e } \\
\text { incentivos não financeiros), condições de trabalho, trabalho } \\
\text { em rede compartilhado, estímulo à autonomia dos envolvidos, } \\
\text { reconhecimento e satisfaçáo profissional, promoçáo dos } \\
\text { envolvidos, envolvimento da equipe na tomada de decisão. }\end{array}$} \\
\hline $\begin{array}{l}\text { Incentivos aos profissionais } \\
\text { do programa }\end{array}$ & \\
\hline $\begin{array}{l}\text { Adaptação de atividades ao } \\
\text { contexto local }\end{array}$ & $\begin{array}{l}\text { Adequação das atividades às necessidades da população/ } \\
\text { comunidade, da organização e ao contexto externo. Percepção } \\
\text { pelos participantes de que o programa está produzindo } \\
\text { os resultados iniciais desejados; adaptação a programas } \\
\text { "concorrentes". }\end{array}$ \\
\hline $\begin{array}{l}\text { Alinhamento aos objetivos } \\
\text { da organização }\end{array}$ & $\begin{array}{l}\text { Programa entre as prioridades de gestão; adequação/ } \\
\text { reorientação entre os objetivos do programa e os objetivos, } \\
\text { valores e missão organizacionais; consenso a respeito dos valores } \\
\text { do sistema. }\end{array}$ \\
\hline $\begin{array}{l}\text { Comunicação transparente } \\
\text { entre os envolvidos com o } \\
\text { programa }\end{array}$ & $\begin{array}{l}\text { Instituição de canais formais e informais de comunicação } \\
\text { (relatórios, correio eletrônico, site, publicaçóes, ouvidoria, } \\
\text { colegiado permanente, entre outros); diálogo permanente com } \\
\text { o controle social, compartilhamento periódico de informaçóes e } \\
\text { evidências sobre o programa. }\end{array}$ \\
\hline $\begin{array}{l}\text { Compartilhamento de } \\
\text { valores }\end{array}$ & $\begin{array}{l}\text { Compartilhamento de valores (símbolos, rituais, linguagem) } \\
\text { comuns entre os atores/organizaçôes envolvidos. }\end{array}$ \\
\hline
\end{tabular}




\begin{tabular}{|c|c|}
\hline Categorias & Definição/critérios \\
\hline $\begin{array}{l}\text { Integração do programa } \\
\text { com as regras/normas } \\
\text { organizacionais }\end{array}$ & $\begin{array}{l}\text { Regulamentação institucional do programa, inserção no } \\
\text { modelo de atenção à saúde, menção em documentos oficiais e } \\
\text { técnicos, inserção do programa no organograma institucional, } \\
\text { nomeação oficial de equipe de coordenação, planejamento } \\
\text { integrado entre o programa e a organização. }\end{array}$ \\
\hline Implantação & \multirow{2}{*}{$\begin{array}{l}\text { Investimento de recursos organizacionais (financeiros, } \\
\text { humanos, materiais/físicos) suficientes/adequados à realização } \\
\text { das atividades, presença de defensores do programa, liderança, } \\
\text { equipe com expertise, carga horária dos profissionais adequada } \\
\text { às atividades. }\end{array}$} \\
\hline $\begin{array}{l}\text { Investimento adequado de } \\
\text { recursos }\end{array}$ & \\
\hline $\begin{array}{l}\text { Práticas e técnicas } \\
\text { compatíveis com as da } \\
\text { organização }\end{array}$ & $\begin{array}{l}\text { Capacidade de transformar requisitos/discurso do programa } \\
\text { em práticas concretas, compatibilidade com outras atividades } \\
\text { organizacionais, compatibilidade de papéis e contribuiçóes da } \\
\text { equipe. }\end{array}$ \\
\hline
\end{tabular}

Fonte: elaboração própria, adaptado de Pluye et al. (2005) e Felisberto et al. (2010).

O presente estudo foi conduzido em conformidade com a Resolução no 466/2012 do Conselho Nacional de Saúde, e aprovado pelo Comitê de Ética em Pesquisa do Instituto de Medicina Integral Prof. Fernando Figueira (IMIP), sob parecer consubstanciado No 1.393.190/2016.

\section{Resultados}

O delineamento da linha do tempo permitiu identificar 14 eventos (E) com características de incidentes críticos (quadro 2). Ao interpretarmos e classificarmos os eventos/incidentes críticos conforme categorias e subcategorias de análise, foram identificados dois eventos que influenciaram a implementação do programa (eventos 1 e 2). Os eventos que influenciam tanto os processos de implementação quanto os de sustentabilidade (mistos) foram em maior número: nove (3 ao 11). E os eventos de sustentabilidade totalizaram três (12 ao 14).

Quanto a serem favoráveis ou náo à sustentabilidade do PAC (em escala cinza no quadro 2), observou-se que a maior parte dos eventos, à exceção dos eventos 9, $10 \mathrm{e}$ 14, teve consequências positivas para a continuidade do programa. 
Quadro 2. Linha do tempo dos eventos/incidentes críticos* (E) segundo categorias e subcategorias de análise e quanto ao fato de ser favorável ou desfavorável à sustentabilidade do PAC, Recife, 2002-2016

\begin{tabular}{|c|c|c|c|c|c|c|c|c|c|c|c|c|c|c|c|}
\hline $\begin{array}{l}\text { Eventos } \\
\text { conceituais }\end{array}$ & ఠิ & ஜे & 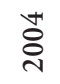 & ڤ̊̀े & : & $\hat{\stackrel{े}{~}}$ & $\stackrel{\infty}{\stackrel{2}{2}}$ & ڤ્ণे & $\stackrel{\circ}{\stackrel{ }{ }}$ & $\overrightarrow{\overline{\overbrace{}}}$ & 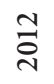 & $\stackrel{n}{\stackrel{n}{\sim}}$ & $\stackrel{\varpi}{\stackrel{\sim}{~}}$ & 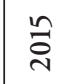 & ্ْণ \\
\hline \multicolumn{16}{|l|}{ Implementação } \\
\hline $\begin{array}{l}\text { Práticas e técnicas } \\
\text { compatíveis com as } \\
\text { da organização }\end{array}$ & & E1 & & & & & & & & & & & & & \\
\hline $\begin{array}{l}\text { Investimento } \\
\text { adequado de } \\
\text { recursos }\end{array}$ & & E2 & & & & & & & & & & & & & \\
\hline \multicolumn{16}{|l|}{$\begin{array}{l}\text { Implementação e } \\
\text { sustentabilidade }\end{array}$} \\
\hline $\begin{array}{l}\text { Integração do } \\
\text { programa com } \\
\text { as regras/normas } \\
\text { organizacionais }\end{array}$ & & E3 & & & & & & & & & & & & & \\
\hline $\begin{array}{l}\text { Alinhamento } \\
\text { aos objetivos da } \\
\text { organização }\end{array}$ & & E4 & & & E8 & & & & & & & & & & \\
\hline $\begin{array}{l}\text { Adaptaçáo de } \\
\text { atividades ao } \\
\text { contexto local }\end{array}$ & & & E5 & & & & & & & & & & & & \\
\hline $\begin{array}{l}\text { Compartilhamento } \\
\text { de valores }\end{array}$ & & & E6 & & & & & & & & & & & & \\
\hline $\begin{array}{l}\text { Comunicaçáo } \\
\text { transparente entre } \\
\text { os envolvidos com } \\
\text { o programa }\end{array}$ & & & & & E7 & & & & & & & & E10 & & \\
\hline $\begin{array}{l}\text { Incentivos à equipe } \\
\text { do programa }\end{array}$ & & & & & & & & & & & & E9 & & E11 & \\
\hline
\end{tabular}

continua... 


\begin{tabular}{|c|c|c|c|c|c|c|c|c|c|c|c|c|c|c|c|}
\hline $\begin{array}{l}\text { Eventos } \\
\text { conceituais }\end{array}$ & ฮิ & ஜ̊ํํ & ஓ্ণ & ஜ̊̊ి & ঃั & હે & ஓ̊ํํ & ڤ્ণ & $\stackrel{\circ}{\circ}$ & 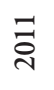 & $\stackrel{2}{8}$ & $\stackrel{n}{\stackrel{2}{\sim}}$ & $\stackrel{\Downarrow}{\stackrel{\sim}{*}}$ & $\stackrel{n}{\text { กิ }}$ & 융 \\
\hline \multicolumn{16}{|l|}{ Sustentabilidade } \\
\hline $\begin{array}{l}\text { Estabilização e/ } \\
\text { ou renovação dos } \\
\text { recursos }\end{array}$ & & & & & & & E12 & & E13 & & & E14 & & & \\
\hline $\begin{array}{l}\text { Riscos assumidos } \\
\text { pela organizaçáa } \\
\text { em prol do } \\
\text { programa }\end{array}$ & & & & & & & & & & & & & & & \\
\hline
\end{tabular}

Fonte: elaboração própria.

*E1-promoção da saúde e humanização: reformulação teórica e prática do PAC (2003); E2-PAC como espaço de formação multiprofissional (2003), E3-instituição e regulamentação do Programa Academia da Cidade (2003), E4-articulação intra e intersetorial (2003), E5-fortalecimento da participação social na gestáo do PAC (2004), E6-reconhecimento nacional e internacional do PAC como experiência exitosa em PS (2004), E7-avaliação da efetividade do PAC (2006), E8-rearranjos organizacionais na equipe do programa (2006), E9-visibilidade do PAC promovendo competiçâo com outras intervençôes (2013), E10-mobilização social em favor do programa (2014-2016), E11-reconfiguração da rede de atores estratégicos ao programa (2014), E12-concurso público para profissionais de educaçáo física (2008), E13cofinanciamento estadual e federal do PAC (2010), e E14-desestabilização do programa com redução dos investimentos (2013-2016).

A seguir, descrevem-se os eventos relativos à sustentabilidade do PAC Recife por tipo de evento (implementação; implementação e sustentabilidade; e sustentabilidade). Cada evento/incidente crítico será abordado segundo elementos comuns, presentes em todas as narrativas. Com objetivo de auxiliar na compreensão de como eles aconteceram: contexto, características, envolvidos/intersetorialidade, e principais acontecimentos (Quadros 3 a 5). 


\section{Quadiro 3. Eventos/incidentes críticos de implementação PAC Recife, 2002-2016}

Evento 1: Promoção da Saúde e Humanização: reformulação teórico-prática do PAC

\begin{tabular}{|l|l|}
\hline Contexto & $\begin{array}{l}\text { Cenário favorável à implantação do PAC, em 2001, quando assume nova gestão } \\
\text { administrativa municipal com projeto de inclusão social por meio de práticas } \\
\text { democráticas e participativas (RECIFE, 2003). }\end{array}$ \\
\hline Características & $\begin{array}{l}\text { Primeira fase (2001): projeto de caráter mais prescritivo e biomédico, apesar de } \\
\text { adotar o discurso da promoçáo da saúde (PS). } \\
\text { Segunda fase (2003): mudanças na gestấo do programa proporcionaram } \\
\text { movimentos favoráveis à sua reconfiguração, adotando mais claramente a } \\
\text { orientaçáo da PS. }\end{array}$ \\
\hline $\begin{array}{l}\text { Envolvidos/ } \\
\text { Intersetorialidade }\end{array}$ & $\begin{array}{l}\text { Participação ativa de alguns profissionais atuantes em programas de outras } \\
\text { secretarias - Círculos Populares de Esporte e Lazer (CPEL) da Secretaria de } \\
\text { Esporte, Turismo e Lazer - na reformulação ocorrida ao longo de 2004. } \\
\text { Discussóes e conflitos de interesse entre atores internos e externos ao programa, } \\
\text { resultando na reorganizaçáa da sua coordenaçáo. }\end{array}$ \\
\hline Principal(is) & $\begin{array}{l}\text { Controvérsia quanto à orientação do programa, mais biomédica ou mais voltada } \\
\text { à PS. A coordenação do PAC lança estratégia de mapeamento territorial, para } \\
\text { promoção de capilaridade do programa, com aproximação dos profissionais } \\
\text { com as comunidades do entorno. Houve redefiniçáo conceitual e prática do } \\
\text { PAC e aplicaçáo das diretrizes de PS. }\end{array}$ \\
\hline
\end{tabular}

Evento 2: PAC como espaço de formação multiprofissional

\begin{tabular}{|c|c|}
\hline Contexto & $\begin{array}{l}\text { Reconhecimento dos limites da formação tradicional dos educadores físicos } \\
\text { quanto às competências requeridas pela nova versão do programa. } \\
\text { A decisão de transformar o programa, conforme diretrizes de PS, trouxe } \\
\text { dissensos entre a equipe do PAC e as instituiçôes de ensino. Isso repercutiu no } \\
\text { distanciamento do programa das instituiçôes locais de ensino. }\end{array}$ \\
\hline Características & $\begin{array}{l}\text { Os esforços na reconfiguração do PAC foram acompanhados de mudanças na } \\
\text { formação permanente de profissionais e estudantes das três áreas envolvidas na } \\
\text { ocasiáo (educaçáo física, nutriçáo e medicina). }\end{array}$ \\
\hline $\begin{array}{l}\text { Envolvidos/ } \\
\text { Intersetorialidade }\end{array}$ & Profissionais e estudantes e as instituiçóes de ensino. \\
\hline $\begin{array}{l}\text { Principal(is) } \\
\text { acontecimento(s) }\end{array}$ & $\begin{array}{l}\text { Oportunidade para discussão das competências necessárias à formação, } \\
\text { principalmente do educador físico, voltada para o Sistema Único de Saúde } \\
\text { (SUS). Como consequência, as instituições de ensino promoveram mudanças na } \\
\text { grade curricular, que passou a contemplar os temas de saúde pública/coletiva. }\end{array}$ \\
\hline
\end{tabular}

Fonte: elaboração própria. 
Quadro 4. Eventos/incidentes críticos de implementação e de sustentabilidade, PAC Recife, 2002-2016

\begin{tabular}{|l|l|}
\hline \multicolumn{2}{|l|}{ Evento 3: Instituição e regulamentação do Programa Academia da Cidade } \\
\hline Contexto & $\begin{array}{l}\text { A partir de 2003, com a remodelação do programa, teve início processo de } \\
\text { reconhecimento interno do mesmo, com ênfase na publicação de normas } \\
\text { regulamentadoras pelo governo municipal. }\end{array}$ \\
\hline Características & $\begin{array}{l}\text { O Decreto Municipal no 19.808/2003 (RECIFE, 2003) instituiu e } \\
\text { regulamentou o programa, e o Decreto Municipal no 22.345/2006 (RECIFE, } \\
\text { 2006) o reconheceu como política de PS, integrante da rede e do modelo de } \\
\text { atenção à saúde municipal. }\end{array}$ \\
\hline $\begin{array}{l}\text { Envolvidos / } \\
\text { Intersetorialidade }\end{array}$ & $\begin{array}{l}\text { A formalizaçáo, por meio do Decreto No 19.808/2003 (RECIFE, 2003), da } \\
\text { parceria intersetorial, em especial com a EMLURB (Empresa de Manutenção } \\
\text { e Limpeza Urbana), foi interpretada como ratificação de uma das principais } \\
\text { características propostas pelo programa: a requalificação dos espaços físicos } \\
\text { públicos. }\end{array}$ \\
\hline $\begin{array}{l}\text { Principal(is) } \\
\text { acontecimento(s) }\end{array}$ & $\begin{array}{l}\text { O arcabouço legal previsto pelos mencionados decretos legitimou a valorização } \\
\text { interna do programa, sendo importante na sua consolidação, tanto pela sua } \\
\text { inserçáo oficial no modelo de atenção à saúde quanto pela criação de condiçóes } \\
\text { para seu 'enraizamento' institucional. }\end{array}$ \\
\hline
\end{tabular}

Evento 4: Articulação intra e intersetorial

\begin{tabular}{|l|l|}
\hline Contexto & $\begin{array}{l}\text { A preocupação com a realização de ações integradas, alinhadas ao projeto } \\
\text { governamental, era uma tônica no discurso oficial do PAC desde suas origens. }\end{array}$ \\
\hline Características & $\begin{array}{l}\text { No âmbito intrainstitucional, o alinhamento se inicia pelos polos integrados } \\
\text { com os Centros de Atenção Psicossocial (CAPS), os quais são equipamentos de } \\
\text { atençáo à saúde mental; e extrainstitucional, com o mencionado CPEL. }\end{array}$ \\
\hline $\begin{array}{l}\text { Envolvidos / } \\
\text { Intersetorialidade }\end{array}$ & $\begin{array}{l}\text { O Grupo Movimento, criado em 2002 por profissionais do PAC, expoente na } \\
\text { integração dos CAPS com o PAC, constituiu-se como um grupo de discussão } \\
\text { sobre temáticas técnico-pedagógicas da educaçáo física, trazendo reflexóes, } \\
\text { inicialmente ausentes do programa, para o seu núcleo gestor. }\end{array}$ \\
\hline $\begin{array}{l}\text { Principal(is) } \\
\text { acontecimento(s) }\end{array}$ & $\begin{array}{l}\text { Em 2002, já funcionavam dois polos integrados ao CPEL, mas, em 2003, essa } \\
\text { parceria se fortaleceu como parte da reconfiguração e da abertura ao diálogo } \\
\text { intersetorial do PAC, uma vez este ser, anteriormente, considerado muito } \\
\text { fechado em suas proposiçóes. }\end{array}$ \\
\hline
\end{tabular}

Evento 5: Fortalecimento da participação social na gestão do PAC

\begin{tabular}{|l|l|}
\hline Contexto & $\begin{array}{l}\text { O reconhecimento das necessidades comunitárias, por meio do mapeamento } \\
\text { territorial, favoreceu a valorização e a incorporação dos saberes locais às práticas } \\
\text { do programa. }\end{array}$ \\
\hline
\end{tabular}




\begin{tabular}{|c|c|}
\hline Características & $\begin{array}{l}\text { A partir de } 2004 \text {, houve intensificação da participação de usuários na gestão do } \\
\text { programa. Eles passaram a utilizar o Orçamento Participativo e as Conferências } \\
\text { de Saúde para cogestão e solicitaçáo de novos polos. }\end{array}$ \\
\hline $\begin{array}{l}\text { Envolvidos / } \\
\text { Intersetorialidade }\end{array}$ & Profissionais e usuários do programa. \\
\hline $\begin{array}{l}\text { Principal(is) } \\
\text { acontecimento(s) }\end{array}$ & $\begin{array}{l}\text { O investimento na requalificação do espaço público passou a produzir } \\
\text { mudanças sociais, permitindo a aplicação de conceitos como inclusão social, } \\
\text { cidadania e empoderamento. Cresceu o interesse partidário em torno do } \\
\text { programa, o qual foi adotado como marca de gestão na campanha eleitoral de } \\
\text { 2004, focada na reeleiçáo. }\end{array}$ \\
\hline \multicolumn{2}{|c|}{ Evento 6: Reconhecimento nacional e internacional do PAC como experiência exitosa em PS } \\
\hline Contexto & $\begin{array}{l}\text { O programa reescrito e aplicado a partir das novas diretrizes (PS) conquistou } \\
\text { premiaçóes nacionais e internacionais. }\end{array}$ \\
\hline Características & $\begin{array}{l}\text { Entre os prêmios destacam-se David Capistrano (2004), concedido pelo MS; } \\
\text { Segundo Concurso Internacional Cidades Ativas, Cidades Saudáveis, promovido } \\
\text { pela Fundação Ciudad Humana, de Bogotá, Colômbia (2005); e prêmio do } \\
\text { Observatório Internacional United Cities and Local Governments (2010). }\end{array}$ \\
\hline $\begin{array}{l}\text { Envolvidos / } \\
\text { Intersetorialidade }\end{array}$ & $\begin{array}{l}\text { Essas premiaçóes trouxeram visibilidade enquanto iniciativa exitosa em PS, } \\
\text { promovendo aproximação entre o programa e outras instituiçóes, com destaque } \\
\text { para o Center for Disease Control and Prevention (CDC) americano e o } \\
\text { Ministério da Saúde (MS). }\end{array}$ \\
\hline $\begin{array}{l}\text { Principal(is) } \\
\text { acontecimento(s) }\end{array}$ & $\begin{array}{l}\text { A aproximação interinstitucional fez com que o programa fosse adotado como } \\
\text { referência na implantaçáo de programas semelhantes em outras localidades } \\
\text { nacionais e internacionais (San Diego, Califórnia, EUA). }\end{array}$ \\
\hline \multicolumn{2}{|c|}{ Evento 7: Avaliação da efetividade do PAC } \\
\hline Contexto & $\begin{array}{l}\text { Em 2006, o MS efetivou convênio com o CDC para realização de pesquisas } \\
\text { sobre a efetividade de programas comunitários de promoção de atividade física, } \\
\text { entre eles o PAC Recife. O MS estava mapeando experiências bem-sucedidas } \\
\text { na área para idealizaçáo da Política Nacional de Promoção da Saúde (PNPS). } \\
\text { Ampliava-se a discussão nacional sobre PS, e gestores do PAC foram convidados } \\
\text { a integrar um grupo de trabalho para construção da referida política. }\end{array}$ \\
\hline Características & $\begin{array}{l}\text { Sobre o PAC Recife foram realizadas quatro pesquisas à época. Elas concluíram, } \\
\text { de um modo geral, que indivíduos que utilizavam o PAC apresentaram maior } \\
\text { probabilidade de serem ativos no período de lazer, e que o grau de satisfação } \\
\text { com o programa mostrou-se elevado entre usuários e profissionais. }\end{array}$ \\
\hline $\begin{array}{l}\text { Envolvidos / } \\
\text { Intersetorialidade }\end{array}$ & $\begin{array}{l}\text { A aproximação do programa com o MS estreitou sua interface com o CDC } \\
\text { como um importante parceiro do programa. }\end{array}$ \\
\hline
\end{tabular}




\begin{tabular}{|c|c|}
\hline $\begin{array}{l}\text { Principal(is) } \\
\text { acontecimento(s) }\end{array}$ & $\begin{array}{l}\text { Os resultados dessas pesquisas, publicados em meios científicos, incluindo } \\
\text { revistas internacionais, serviram para ratificar (com base em evidências) os } \\
\text { resultados observados na prática, fortalecendo também sua divulgação. }\end{array}$ \\
\hline \multicolumn{2}{|c|}{ Evento 8: Rearranjos organizacionais na equipe do programa } \\
\hline Contexto & $\begin{array}{l}\text { À exceção do trabalho compartilhado nos CAPS, as açóes com outros } \\
\text { equipamentos de saúde eram pontuais. Foram propostos, a partir de } 2006 \text {, } \\
\text { novos arranjos organizacionais na equipe, de modo que os educadores físicos } \\
\text { fortalecessem alianças na rede de saúde. }\end{array}$ \\
\hline Características & $\begin{array}{l}\text { Houve redistribuição dos profissionais de nutrição e de medicina do PAC para } \\
\text { outros serviços da rede municipal de saúde. }\end{array}$ \\
\hline $\begin{array}{l}\text { Envolvidos / } \\
\text { Intersetorialidade }\end{array}$ & $\begin{array}{l}\text { Com a saída do nutricionista exclusivo, os educadores físicos realizam } \\
\text { orientação voltada à alimentação saudável, entretanto, de maneira incipiente. } \\
\text { Com a implantação municipal, em } 2010 \text {, dos Núcleos de Apoio à Saúde } \\
\text { da Família, em alguns polos, vêm sendo desenvolvidas parcerias na área de } \\
\text { alimentação e nutrição. }\end{array}$ \\
\hline $\begin{array}{l}\text { Principal(is) } \\
\text { acontecimento(s) }\end{array}$ & $\begin{array}{l}\text { Mesmo com as mudanças na equipe, o programa continuou isolado. Os } \\
\text { horários diferentes dos da rede de saúde, além da não inserção de outros } \\
\text { profissionais (equipe multiprofissional) nos moldes propostos pelo MS, } \\
\text { dificultam a articulação intrasetorial. }\end{array}$ \\
\hline \multicolumn{2}{|c|}{ Evento 9: Visibilidade do PAC promovendo competição com outras intervenções } \\
\hline Contexto & $\begin{array}{l}\text { No período analisado houve duas mudanças de governo municipal ( } 2010 \text { e } \\
\text { 2013). A segunda mudança (político partidária/nova gestão) foi compreendida } \\
\text { como "ruptura política", onde o PAC passa a não gozar do mesmo prestígio, } \\
\text { com interpretação do programa como "marca da gestão anterior". }\end{array}$ \\
\hline Características & $\begin{array}{l}\text { Nessa fase, foram implantados dois programas voltados ao estímulo à atividade } \\
\text { física (AF): a ciclofaixa e o Programa Academia Recife, ambos ligados à } \\
\text { Secretaria de Turismo, Esportes e Lazer. }\end{array}$ \\
\hline $\begin{array}{l}\text { Envolvidos / } \\
\text { Intersetorialidade }\end{array}$ & $\begin{array}{l}\text { Esse movimento não representou a integração intersetorial esperada entre o PAC } \\
\text { e tais programas, nos moldes institucionais à época do CPEL. }\end{array}$ \\
\hline $\begin{array}{l}\text { Principal(is) } \\
\text { acontecimento(s) }\end{array}$ & $\begin{array}{l}\text { Houve percepção de o PAC ter sido preterido face aos dois novos programas, } \\
\text { com não reconhecimento da sua história e seus resultados positivos. Isso trouxe } \\
\text { desmotivaçáo aos profissionais do PAC. }\end{array}$ \\
\hline \multicolumn{2}{|c|}{ Evento 10: Mobilização social em favor do programa } \\
\hline Contexto & $\begin{array}{l}\text { Dado o déficit de condiçóes organizacionais, materiais e de recursos humanos, } \\
\text { agravado durante o período da nova gestão, iniciou-se, a partir de } 2014 \text {, novo } \\
\text { pico de participaçáo social com intensa mobilizaçáo em favor do programa. }\end{array}$ \\
\hline
\end{tabular}




\begin{tabular}{|l|l|}
\hline Características & $\begin{array}{l}\text { Utilizaram-se diversos canais de gestão participativa, como as instâncias de } \\
\text { controle social (Conselhos e Conferências de Saúde), Câmara de Vereadores } \\
\text { (Audiências Públicas), Ouvidoria, entre outros. }\end{array}$ \\
\hline $\begin{array}{l}\text { Envolvidos / } \\
\text { Intersetorialidade }\end{array}$ & $\begin{array}{l}\text { Esses movimentos apresentaram protagonismo da Associação de Profissionais } \\
\text { de Educaçáo Física de Pernambuco, responsável por mobilizar profissionais e } \\
\text { usuários. }\end{array}$ \\
\hline $\begin{array}{l}\text { Principal(is) } \\
\text { acontecimento(s) }\end{array}$ & $\begin{array}{l}\text { A chegada dos materiais de apoio às aulas, em junho de 2016, foi interpretada } \\
\text { como fruto de muita reivindicaçấo. }\end{array}$ \\
\hline Evento 11: Reconfiguração da rede de atores estratégicos para o programa \\
\hline Contexto & $\begin{array}{l}\text { Em meados de 2014, iniciou-se a reaproximação do PAC a uma das instituiçóes } \\
\text { de ensino que participara da sua origem. O mote foi a parceria para realização } \\
\text { de curso de especialização para os profissionais dos polos. }\end{array}$ \\
\hline Características & $\begin{array}{l}\text { As pesquisas, produtos da conclusão desta pós-graduaçáo, foram úteis na } \\
\text { identificaçáo de entraves e aplicaçáo de soluçóes. }\end{array}$ \\
\hline $\begin{array}{l}\text { Envolvidos / } \\
\text { Intersetorialidade }\end{array}$ & $\begin{array}{l}\text { Essa reaproximação foi tida como importante, já que o afastamento (em meados } \\
\text { de 2003) trouxe repercussóes no suporte conceitual para o programa. Essa } \\
\text { instituiçấo de ensino também passou a se engajar na "luta" pelo programa. }\end{array}$ \\
\hline $\begin{array}{l}\text { Principal(is) } \\
\text { acontecimento(s) }\end{array}$ & $\begin{array}{l}\text { Os resultados de algumas dessas pesquisas foram compartilhados. Apesar } \\
\text { de apenas internamente (resultados endógenos). Houve reativação de polo } \\
\text { universitário experimental, além da revisão conjunta do protocolo de avaliação } \\
\text { física. }\end{array}$ \\
\hline
\end{tabular}

Fonte: elaboração própria.

\section{Quadro 5. Eventos/incidentes críticos de sustentabilidade, PAC Recife, 2002-2016}

Evento 12: Concurso público para profissionais de educação física

\begin{tabular}{|l|l|}
\hline Contexto & $\begin{array}{l}\text { Em que pese o reconhecimento interno e externo que o PAC começara a } \\
\text { ter a partir de 2005, a precariedade do vínculo profissional era um aspecto } \\
\text { emblemático, tido, na ocasião, como entrave à sua sustentabilidade. }\end{array}$ \\
\hline Características & $\begin{array}{l}\text { As evidências sobre o programa, obtidas pelas pesquisas sobre sua efetividade, } \\
\text { e a avaliação positiva pela população, além da sua previsão legal, favoreceram } \\
\text { investimentos no programa, com ênfase para a regulação do trabalho dos } \\
\text { profissionais dos polos. }\end{array}$ \\
\hline $\begin{array}{l}\text { Envolvidos / } \\
\text { Intersetorialidade }\end{array}$ & Secretaria Municipal de Saúde e profissionais do programa. \\
\hline $\begin{array}{l}\text { Principal(is) } \\
\text { acontecimento(s) }\end{array}$ & $\begin{array}{l}\text { A realização, em 2008, de concurso público para profissionais de educação } \\
\text { física acarretou diversas consequências à gestáo do PAC, sendo a estabilidade do } \\
\text { vínculo profissional a principal delas. }\end{array}$ \\
\hline
\end{tabular}




\begin{tabular}{|c|c|}
\hline \multicolumn{2}{|c|}{ Evento 13: Cofinanciamento estadual e federal do PAC } \\
\hline Contexto & $\begin{array}{l}\text { Utilizando o PAC como modelo, o governo estadual instituiu em 2007, com } \\
\text { o apoio do MS e do CDC, o Programa Academia das Cidades. Anos mais } \\
\text { tarde (2010), o PAC foi reconhecido pela esfera federal como importante na } \\
\text { concepçáo do Programa Academia da Saúde no âmbito nacional. }\end{array}$ \\
\hline Características & $\begin{array}{l}\text { A instituição desses dois programas promoveu cofinanciamento tripartite para } \\
\text { o PAC, muito embora o município arque com a maior parte das despesas, além } \\
\text { de não haver definição de recursos municipais próprios, desde a origem do } \\
\text { programa. }\end{array}$ \\
\hline $\begin{array}{l}\text { Envolvidos / } \\
\text { Intersetorialidade }\end{array}$ & Governos estadual e federal. \\
\hline $\begin{array}{l}\text { Principal(is) } \\
\text { acontecimento(s) }\end{array}$ & $\begin{array}{l}\text { O financiamento compartilhado foi visto como importante na sustentabilidade } \\
\text { financeira do programa. Houve intensa expansão do programa, que inaugurou, } \\
\text { em 2012, } 21 \text { novos polos em parceria com o Governo do Estado. }\end{array}$ \\
\hline \multicolumn{2}{|c|}{ Evento 14: Desestabilização do programa com redução dos investimentos } \\
\hline Contexto & $\begin{array}{l}\text { O período da nova gestáo (a partir de 2013) representou um momento } \\
\text { com menos investimentos em recursos físicos, materiais e organizacionais } \\
\text { para o PAC, o que chegou a comprometer a realização das atividades, com } \\
\text { desmotivação de profissionais e usuários. }\end{array}$ \\
\hline Características & $\begin{array}{l}\text { A demora na aquisição dos recursos materiais ( } 2013 \text { a 2016) foi atribuída, por } \\
\text { parte da Secretaria Municipal de Saúde, a entraves inerentes à gestão pública. }\end{array}$ \\
\hline $\begin{array}{l}\text { Envolvidos / } \\
\text { Intersetorialidade }\end{array}$ & Secretaria Municipal de Saúde, profissionais dos polos, usuários. \\
\hline $\begin{array}{l}\text { Principal(is) } \\
\text { acontecimento(s) }\end{array}$ & $\begin{array}{l}\text { O fato de a chegada dos recursos materiais ter sido coincidente com o período } \\
\text { em que o governo municipal pleiteava a reeleiçáo reforçou a relaçáo do } \\
\text { programa com questóes partidárias. Permaneceu o déficit de profissionais para } \\
\text { os polos, uma vez no período estudado não ter havido novos concursos. }\end{array}$ \\
\hline
\end{tabular}

Fonte: elaboração própria.

\section{Discussão}

A ocorrência de dois eventos de implementação (favoráveis) em 2003 (eventos 1 e 2-promoção da saúde e humanização: reformulação teórica e prática do PAC, e PAC como espaço de formação multiprofissional, respectivamente), foi decisiva no desenvolvimento do PAC enquanto política municipal de PS, contribuindo para o fortalecimento de aspectos teóricos e práticos estruturadores desse ponto em diante. A reformulação das suas diretrizes (evento 1) repercutiu na maior parte dos eventos 
identificados, com mais força nos ocorridos até meados de 2012, sendo considerado um marco. Esse evento traduziu a capacidade do PAC de transformar seu discurso em prática ao início do seu processo de implantação. Tal capacidade, segundo Pluye et al. (2005), é fundamental na compatibilidade técnica entre um programa e a organização que o abriga, contribuindo para seu 'enraizamento' institucional.

A formação permanente (evento 2), ao ser reformulada conforme as novas diretrizes, e as necessidades de formação permitiram que esse espaço se mantivesse como legitimado. Investimentos na formação permanente demonstraram em outros estudos (PLUYEetal.2005; SHEDIAC-RIZKALLAH;BONE, 1998; DENIS, 2010) serem importantes na continuidade de programas. A manutenção das capacidades, de forma duradoura, leva a que os profissionais continuem proporcionando benefícios, assim como contribuam no fortalecimento de capacidades comunitárias num círculo virtuoso de retroalimentação. No caso estudado, observou-se que as inovaçôes promovidas extrapolaram a esfera do programa, com incorporaçáo das novas diretrizes propostas nos currículos universitários locais, além da expansão, para outras localidades nacionais e internacionais, dos eventos 6 e 13 (HALLAL et al., 2007; FEITOSA, 2015).

Quanto aos eventos de implementação e de sustentabilidade (mistos), a maior parte deles foi considerada favorável. Pode-se conceber que muitos deles (eventos 3 , 4, 5, 6 e 8) estiveram bastante alinhados às diretrizes do projeto político da gestão que idealizou o programa, tais como gestão participava e inclusão social. Isso pode ser considerado um diferencial na direção de decisóes acertadas que obtiveram êxito no período de 2002 a 2012, e que cooperaram no desenvolvimento e na projeção/difusão do programa nas esferas estadual, nacional e internacional, com o compartilhamento de valores entre os envolvidos.

A exceção desse processo foram os rearranjos organizacionais na equipe do programa, efetivados a partir de 2006 (evento 8). Esses objetivavam fortalecer um dos pilares do referido projeto político: ações integradas em rede, mas que não conseguiram efetivar-se plenamente, nos moldes desenvolvidos entre CAPS e o PAC, onde a presença do educador físico na equipe apresenta diversas contribuiçóes para os usuários, como reinserção e socialização, e participação em projetos terapêuticos singulares (SOARES et al., 2016).

$\mathrm{O}$ apoio organizacional, para além do financeiro, é considerado pela literatura como fator estratégico na sustentabilidade, contribuindo para a construção de 
confiança entre os envolvidos e na integração do programa à missão organizacional (PLUYE et al., 2004; PLUYE et al., 2005; SCHEIRER, 2005; SCHELL et al., 2013). Como parte desse apoio, está a formalização do programa nas normas e regras organizacionais (evento 3), uma vez serem mais sustentáveis aqueles que se baseiem em procedimentos escritos (PLUYE et al., 2005; FELISBERTO et al., 2010). O fato de o PAC ter se originado da "necessidade" dos envolvidos na sua operação, num processo colaborativo com outros atores internos e externos - bottom up (HARTZ, 2015) fortaleceu ainda mais sua integração organizacional no período (de 2002 a 2012) e, consequentemente, sua continuidade. Para alguns autores (SHEDIAC-RIZKALLAH; BONE, 1998; SCHEIRER, 2005), intervençôes não verticalizadas têm mais oportunidades de prosseguimento.

A literatura demonstra que a flexibilidade de uma intervenção se modificar conforme o contexto local, com percepção de que ela está produzindo os resultados iniciais desejados, e com apoio de membros comunitários, é condição crítica na prestação de serviços continuados (SHEDIAC-RIZKALLAH; BONE, 1998; PLUYE et al., 2004, PLUYE et al., 2005; SCHEIRER, 2005; SCHELL et al., 2013). A criação de vínculo entre profissionais dos polos e usuários, fortalecida durante o evento 5 (participação social), e a adaptação do programa às necessidades desses últimos, conformaram uma rede de atores, com características de coalização comunitária (SCHEIRER, 2005).

O estabelecimento de parcerias intra e intersetoriais (evento 4), apesar da sua intermitência em determinados períodos, também foi fundamental na conformação dessa rede, promovendo engajamento contínuo dos interessados. Na opinião de Schell et al. (2013), esse engajamento amplifica o ajuste/adaptação entre a intervenção e o contexto local.

A realização de pesquisas sobre a efetividade do programa (eventos 7 e 11) contribuiu para a consolidação e qualificação do programa no município. Oliveira et al. (2017) concluíram em seu estudo que a avaliação é essencial nesse aspecto, uma vez que suas conclusóes devem informar a evolução das intervençôes e gerar novas práticas (baseadas em evidências), podendo servir também para assegurar financiamentos futuros. No caso do PAC, essa assertiva foi ratificada quando da ocorrência do evento 13 (cofinanciamento estadual e federal do PAC).

A partir de 2012, com as duas mudanças de gestão municipal, o PAC passa a não estar mais alinhado aos projetos políticos inerentes, não estando, portanto, entre 
as prioridades de investimento (PLUYE et al., 2005). Chama atenção a "ruptura" ocorrida quando da segunda mudança em 2013 (de partido de oposição). Esta última criou dois programas de estímulo à atividade física, acarretando desmotivação dos profissionais do PAC, pela percepção de competição entre ele e essas intervençôes (evento 9). A ocorrência desse evento, juntamente com o evento 14 (desestabilização do programa com redução dos investimentos), promoveu momento de instabilidade do programa no município, constituindo-se numa ameaça à sua continuidade.

Os eventos de realização de concurso público para profissionais de educação física em 2008 (evento 12) e de cofinanciamento estadual e federal do PAC a partir de 2010 (evento 13) trouxeram estabilidade para o programa, sendo considerados favoráveis à sustentabilidade. Em oposição à sua desestabilização, ocorrida de 2013 a 2016, quando houve redução no investimento em recursos organizacionais e materiais (evento 14).

A equipe à frente da intervenção tem papel de destaque na sustentabilidade. Além da formação permanente, seu envolvimento na tomada de decisão favorece o sentimento de pertencimento e motivação. Nesse aspecto, a partir de 2012, com a transição de gestóes municipais, a cogestáo e a coanálise ficaram prejudicadas. Houve diminuição da participação da equipe no processo de negociação relativa à intervenção, o que interferiu na autonomia profissional. Por outro lado, a característica estável da força de trabalho foi considerada um contraponto no bojo dessas dificuldades, posto que a literatura indica que a estabilidade profissional é um fator determinante na sustentabilidade (OLIVEIRA; POTVIN; MEDINA, 2015; OLIVEIRA et al., 2017).

O financiamento também se destaca na direção da institucionalização, sendo marcado como primordial. O fato de o PAC apresentar duas outras fontes de financiamento externas sem, no entanto, ser dependente delas, foi importante na garantia de recursos regulares para o programa. Entretanto, a indefinição de dotação orçamentária própria e o investimento insuficiente de recursos foram importantes na instabilidade ocorrida entre 2012 e 2016. Conforme Schell et al. (2013), diversas intervençôes de PS estáo fadadas à interrupção devido a recursos insuficientes. Para Scheirer (2005), em períodos de financiamento escasso, não se pode supor que os serviços prestados, e consequentemente os benefícios para os usuários, continuem no mesmo patamar. Dessa forma, conjectura-se que os benefícios atribuídos ao programa só puderam ser retomados em 2016, quando da chegada dos recursos materiais. 


\section{Considerações finais}

A análise dos eventos relativos a sustentabilidade/incidentes críticos do PAC Recife nos permitiu concluir que ele passou um período de intensa expansão, difusão e alinhamento institucional até meados de 2012, quando mudanças no contexto político municipal trouxeram um arrefecimento nas discussôes internas a seu respeito, com implicaçóes no seu processo de implementação e estabilidade.

A instabilidade sofrida pela intervenção, desse ano em diante, foi superada pela ocorrência de fatos/situaçôes cujas consequências positivas permitiram um movimento de reconfiguração do programa, os quais foram decisivos na sua manutenção no período estudado.

Os fatores positivos mencionados como recursos financeiros advindos de múltiplas fontes, adaptação do programa conforme o contexto local, investimento na formação permanente e na autonomia da equipe, baixa rotatividade dos profissionais qualificados e formaçáo de alianças com características de rede de "liderança influente" - estiveram alinhados ao mencionado pela literatura como fatores influentes na sustentabilidade de intervençôes de PS.

Constatou-se que a intervenção estudada "resistiu" às mudanças de governo municipal, ampliando seu escopo de atuação ao longo do tempo, com conformação de parcerias em diferentes níveis - em especial no âmbito local - passando de um projeto a uma política pública municipal de PS, que serviu de referência para adoção de políticas semelhantes nos âmbitos estadual, federal e internacional.

Recomenda-se a realização de estudos empíricos em outros contextos, que demonstrem diferenças ou semelhanças com os fatores considerados positivos, pelo presente estudo, na sustentabilidade de intervençóes de PS. A condução de novas pesquisas nacionais teria um campo fértil a ser explorado, tendo em vista o quantitativo de iniciativas de PS/atividade física no país, que, inclusive, contam com indução do governo federal para sua implantação, em contraponto com os poucos estudos que avaliem sua sustentabilidade. ${ }^{2}$

\section{Referências}

BARDIN, L. Análise de conteúdo. Lisboa: edições 70, 2011.

BISSET, S. L.; POTVIN L. Expanding our conceptualization of program implementation: lessons from the genealogy of a school-based nutrition program. Health Educacion Research, v. 22, p. 737-746, 2007. 
DENIS, J. L. Institucionalização da avaliação na administração pública. Revista Brasileira de Saúde Materno-Infantil, v. 10, supl. 1, p. S229-S237, 2010.

DIJKMAN, M. A. M. et al. Sustainability of the good behaviour game in Dutch primary schools. Health Promotion International, v. 32, n. 1, p. 1-12, 2015.

FEITOSA, W. M. N. Programas de Promoção da Atividade Física: estudo de caso acerca da implementação do Programa Academia da Cidade (PAC) em Recife entre 2002 e 2014. Tese (Doutorado) - Instituto de Pesquisas Aggeu Magalhães, Fundação Oswaldo Cruz, Recife, 2015.

FELISBERTO, E. et al. Análise da sustentabilidade de uma política de avaliação: o caso da atenção básica no Brasil. Cadernos de Saúde Pública, v. 26, n. 6, p. 1079-1095, 2010.

FIGUEIRÓ, A. C. et al. Formação de Avaliadores e o estudo das intervençôes inovadoras em Saúde: o caso do Programa Academia da Cidade. In: BRASIL. Conselho Nacional de Secretários de Saúde. Avaliação em promoção da saúde: uma antologia comentada da parceria entre o Brasil e a cátedra de abordagens comunitárias e iniquidades em saúde (CACIS), da Universidade de Montreal de 2002 a 2012. Brasília: CONASS, 2014. p. 170-190.

FLANAGAN, J. C. A técnica dos incidentes críticos. Arquivos Brasileiros de Psicologia Aplicada, v. 25, p. 99-141, 1973.

HALLAL, P. C. et al. Evolução da pesquisa epidemiológica em atividade física no Brasil: revisão sistemática. Revista de Saúde Pública, v. 41, n. 3, p. 453-60, 2007.

HARTZ, Z. M. A. Contextualizando a implantação de intervençóes e da avaliação em saúde: um ensaio pragmático. In: SAMICO I. C. et al. (Orgs.). Formação profissional em avaliação em saúde: desafios na implantação de programas. Rio de Janeiro: MedBook, 2015. p. 3-20.

HARTZ, Z. M. A.; SANTOS, E. M.; MATIDA, A. H. Promovendo e analisando o uso e a influência das pesquisas avaliativas, In: HARTZ, Z. M. A.; FELISBERTO, E.; SILVA, L. M. V. (Orgs.). Meta-avaliação da Atenção Básica, Rio de Janeiro: Fiocruz, 2008. p. 169-187.

HSIEH, H-F.; SHANNON, S. E. Three Approaches to Qualitative Content Analysis. Qualitative Health Research, v. 15, p. 1277-1288, 2005.

JOLY, P. B. et al. ASIRPA: A comprehensive theory-based approach to assessing the societal impacts of a research organization. Research Evaluation, v. 24, n. 4, p. 1-14, 2015.

MENDES, R. et al. Promoção da saúde na metrópole com foco na intersetorialidade e sustentabilidade. Tempus Acta Saúde Coletiva, v. 8, n. 3, p. 125-143, 2014.

O'LOUGHLIN, J. et al. Correlates of the sustainability of community-based heart health promotion interventions. Preventive Medicine, v. 27, n. 5, p. 702-712, 1998.

OLIVEIRA, S. R. A. et al. Strategic factors for the sustainability of a health intervention at municipal level of Brazil. Cadernos de Saúde Pública, v. 33, n. 7, p. 1-11, 2017. 
OLIVEIRA, S. R. A.; POTVIN, L.; MEDINA, M. G. Sustentabilidade de intervenções em promoção da saúde: uma sistematização do conhecimento produzido. Revista Saúde em Debate, v. 39, n. 107, p. 1149-1161, 2015.

PLUYE, P. et al. Making public health programs last: conceptualizing sustainability. Evaluation Program Plann, v. 27, p. 121-33, 2004.

PLUYE, P. et al. Program sustainability begins with the first events. Evaluation Program Plann, v. 28, p. 123-137, 2005.

PLUYE, P.; POTVIN, L.; DENIS, J-L. Making public health programs last: conceptualizing sustainability. Evaluation Program Plann, v. 27, p. 121-33, 2004.

POTVIN, L.; CHABOT, P. Splendor and misery of epidemiology for the evaluation of health promotion. Revista Brasileira de Epidemiologia, v. 5, supl. 1, p. 91-102, 2002.

RECIFE. Secretaria Municipal de Saúde. Decreto no 19.808, de 3 de abril de 2003. Institui e regulamenta o Programa Academia da Cidade. Recife, 2003. Disponível em: <http://www. legiscidade.recife.pe.gov.br/decreto/19808/>. Acesso em: 6 mar. 2016.

RECIFE. Secretaria Municipal de Saúde. Decreto no 22.345, de 18 de outubro de 2006. Reestrutura o Regulamento do Programa Academia da Cidade. Recife, 2006. Disponível em: <http://www.legiscidade.recife.pe.gov.br/decreto/22345/>. />. Acesso em: 6 mar. 2016.

SCHEIRER, M. A. Is sustainability possible? A review and commentary on empirical studies of program sustainability. American Journal Evaluation, v. 26, p. 320-347, 2005.

SCHEIRER, M. A.; DEARING, J. W. An agenda for research on the sustainability of public health programs. American Journal Public Health, v. 101, n. 11, p. 2059-2067, 2011.

SCHELL, S. F. et al. Public health program capacity for sustainability: a new framework. Implementation Science, v. 8, n. 1, p. 1-15, 2013.

SHEDIAC-RIZKALLAH, M. C.; BONE, L. R. Planning for the sustainability of communitybased health programs: conceptual frameworks and future directions for research, practice and policy. Health Education Research, v. 13, n. 1, p. 87-108, 1998.

SOARES, S. E. T. O. M. et al. Contributions and challenges of physical education professionals at the Center for Psychosocial Support. Revista Brasileira de Atividade Fisica e Saúde, v. 21, n. 5, p. 420-430, 2016.

YIN, R. K. Estudo de caso: planejamento e métodos. 5 ed. Porto Alegre: Bookman, 2015. 


\section{Notas}

${ }^{1}$ Esta pesquisa não recebeu auxílio financeiro e é produto de tese de doutorado intitulada Avaliação da Contribuição e da Sustentabilidade do Programa Academia da Cidade no Município de Recife, Pernambuco, Brasil, integrante do Programa de Doutoramento em Saúde Internacional do Instituto de Higiene e Medicina Tropical, da Universidade Nova de Lisboa. As autoras agradecem à equipe da Secretaria Municipal de Saúde do Município de Recife, pela colaboraçấo na realização deste estudo.

${ }^{2}$ G. Cazarin e A. C. Figueiró contribuíram na concepção e planejamento do estudo; na análise e interpretação dos dados. S. F. Dias elaborou o rascunho e a revisão crítica do conteúdo. Z. Hartz aprovou a versão final do artigo. 


\section{Abstract}

\section{Sustainability analysis of a health promotion intervention in Recife-PE, Brazil}

Initiatives for promotion of physical activity have been identified as relevant practices in health promotion. The city of Recife-PE, devised and implemented in 2002 a policy called Academia da Cidade Program (ACP). The sustainability of health promotion interventions imposes a challenge to the maintenance of its results. The goal was to analyze the course of events related to the sustainability of the ACP Recife from 2002 to 2016. It is a qualitative evaluative research with a single case study strategy. For data analysis, the thematic content was used. Data was collected using the critical incident technique from 14 interviews with key informants and six focal groups in two periods: from August to December 2010, and June to August 2016; and technical and official documents. A timeline for critical events/incidents related to the program sustainability was created. Data were analyzed according to the following categories: sustainability, mixed and implementation events. Events were classified according to their consequences: favorable or unfavorable to sustainability. The results pointed out to the occurrence of 14 critical events/incidents, most of them with positive consequences to the continuity of the program in the period.

> Keywords: health assessment; sustainability; health promotion. 